Proceedings

\title{
Characterization of Methanosarcina mazei JL01 isolated from Holocene Arctic Permafrost and study of the archaeon cooperation with bacterium Sphaerochaeta associata GLS2T
}

\author{
Viktoriia Oshurkova ${ }^{* 1}$, Olga Troshina ${ }^{1}$, Vladimir Trubitsyn ${ }^{1}$, Yana Ryzhmanova ${ }^{1}$, Olga \\ Bochkareva $^{2}$ and Viktoria Shcherbakova ${ }^{1}$ \\ 1. Skryabin Institute of Biochemistry and Physiology of Microorganisms, Federal Research Center Pushchino \\ Center for Biological Research of the Russian Academy of Sciences, prospect Nauki 5, Pushchino, 142290, \\ Moscow Region, Russia; oshurkova.viktoriya@gmail.com (V.O.); oltro676@yandex.ru (O.T.); \\ lichoradkin43@gmail.com (V.T.); ryzhmanova@gmail.com (Y.R.); vshakola@gmail.com (V.S.) \\ 2Institute of Science and Technology (IST Austria), Am Campus 1, 3400 Klosterneuburg, Austria; \\ olga.bochkaryova@gmail.com \\ ${ }^{*}$ Corresponding author \\ Presented at the 1st International Electronic Conference on Microbiology, 2-30 November 2020; Available \\ online: https://ecm2020.sciforum.net/ \\ Published: 02 November 2020
}

\begin{abstract}
A mesophilic methanogenic culture, designated JL01, was isolated from Holocene permafrost in the Russian Arctic [1]. After long-term extensive cultivation at $15^{\circ} \mathrm{C}$ it turned out to be a tied binary culture of archaeal (JL01) and bacterial (Sphaerochaeta associata GLS2) strains. Strain JL01 was a strict anaerobe and grew on methanol, acetate and methylamines as energy and carbon sources. Cells were irregular coccoid, non-motile, non-spore-forming, and Gram-stainpositive. Optimum conditions for growth were $24-28{ }^{\circ} \mathrm{C}, \mathrm{pH}$ 6.8-7.3 and 0.075-0.1 M NaCl . Phylogenetic tree reconstructions based on $16 \mathrm{~S}$ rRNA and concatenated alignment of broadly conserved protein-coding genes revealed its close relation to Methanosarcina mazei S- $6^{\mathrm{T}}$ (similarity $99.5 \%$ ). The comparison of whole genomic sequences (ANI) of the isolate and the type strain of $M$. mazei was $98.5 \%$, which is higher than the values recommended for new species. Thus strain JL01 (=VKM B-2370=JCM 31898) represents the first $M$. mazei isolated from permanently subzero Arctic sediments. The long-term co-cultivation of JL01 with S. associata GLS2T showed the methane production without any additional carbon and energy sources. Genome analysis of S. associata GLS2 ${ }^{\mathrm{T}}$ revealed putative genes involved in methanochondroithin catabolism.
\end{abstract}

Keywords: archaea; methanogens; permafrost; Methanosarcina sp., Sphaerochaeta associata; metabolic cooperation

\section{Introduction}

Methanogens are a unique and the only group of microorganisms responsible for the generation of all biogenic methane of the Earth. These archaea use very small range of substrates and they are highly adaptable to various harsh conditions, even extreme environments. Research of Arctic permafrost revealed the presence of viable methanogenic archaea [2]. The use of cultivation methods made it possible to identify and describe new methanogenic species of the genera Methanosarcina and Methanobacterium in the Pliocene and Pleistocene permafrost, which are responsible for the formation of methane under extreme subzero conditions [3-5]. The results of the metagenomic sequencing of two samples of permafrost sediments suggested that the composition of the archaeal community and the presence of methanogens in it, mainly represented by the Methanosarcinaceae and 
Methanobacteriaceae families, are determined by permafrost origin [6]. Many methanogenes are known to be involved in tight metabolic and syntrophic associations [7]. Earlier we isolated coccoid spirochaete Sphaerochaeta associata GLS2 $^{\mathrm{T}}$ from long-term stable methanogenic enrichment culture JL01. In this article we show that Methanosarcina sp. JL01 produces methane in cooperation with saccharolytic bacterial partner Sphaerochaeta associata GLS2 ${ }^{\mathrm{T}}$ without any carbon and energy sources, added in the medium. Also we present more detailed characterization of strain JL01 [1], and prove that it is a representative of the first Methanosarcina strain isolated from permafrost.

\section{Materials and Methods}

\subsection{Enrichment and isolation}

Methane-producing culture JL01 was isolated from the 2.0-m-deep Holocene permafrost sample, collected in the Russian North East Arctic $\left(70^{\circ} 06^{\prime} \mathrm{N}, 154^{\circ} 04^{\prime} \mathrm{E}\right)$ between the Lena delta and the mouth of the Kolyma river in 2000 [1]. Pure culture of methanogenic strain was maintained in an anaerobic MSG medium containing (l-1): $5.0 \mathrm{~g} \mathrm{NaCl}, 0.2 \mathrm{~g} \mathrm{MgCl}_{2} \times 6 \mathrm{H}_{2} \mathrm{O}, 1.0 \mathrm{~g} \mathrm{NH} 4 \mathrm{Cl}, 0.1 \mathrm{~g} \mathrm{CaCl}_{2} \times 2 \mathrm{H}_{2} \mathrm{O}, 1.5 \mathrm{~g}$ $\mathrm{KH}_{2} \mathrm{PO}_{4}, 2.5 \mathrm{~g} \mathrm{~K} 2 \mathrm{HPO}_{4} \times 3 \mathrm{H}_{2} \mathrm{O}, 1.0 \mathrm{~g}$ Casamino acids, $10 \mathrm{ml}$ vitamin solution (medium 141; DSMZ), 10 $\mathrm{ml}$ trace element solution (medium 141; DSMZ), $10 \mathrm{ml} ; 0.001 \mathrm{~g}$ resazurine, $0.25 \mathrm{~g}$ cysteine hydrochloride hydrate, $0.25 \mathrm{~g} \mathrm{Na} 2 \mathrm{~S} \times 9 \mathrm{H}_{2} \mathrm{O}, 4.0 \mathrm{~g}$ sodium acetate trihydrate and kanamycin $\left(150 \mathrm{mg} \mathrm{l}^{-}\right.$ $\left.{ }^{1}\right)$. The strain purity was confirmed by light microscope examination, the absence of growth in MSG medium containing glucose $\left(2 \mathrm{gL}^{-1}\right)$ and peptone $\left(2 \mathrm{gL}^{-1}\right)$ from which the acetate and kanamycin were omitted.

\subsection{Phenotypic, physiological and biochemical characterization}

All morphological and physiological characteristics of strain JL01 were determined according to the minimal standards for description of new taxa of archaea [8]. The cell morphology was examined using a Lumam I-2 microscope (LOMO, Russia) in phase contrast mode using 90×15 magnification and a JEM-100 electron microscope (JOEL, Japan). The methanogen isolate was investigated for the growth at $\mathrm{pH}(4-9)$, temperature $\left(0-50^{\circ} \mathrm{C}\right)$ and sodium chloride requirement $(0-0.5 \mathrm{M})$. To determine the utilization of different carbon substrates as energy source, a basal MSG medium supplemented with one of the tested substrate was used: $20 \mathrm{mM}$ propionate, $20 \mathrm{mM}$ butyrate, $\mathrm{H}_{2} / \mathrm{CO}_{2}(80: 20,1.5$ atm), $100 \mathrm{mM}$ methanol, $50 \mathrm{mM}$ formate, $50 \mathrm{mM}$ acetate, $20 \mathrm{mM}$ ethanol, $20 \mathrm{mM}$ 2-propanol, $20 \mathrm{mM}$ 2-butanol, $50 \mathrm{mM}$ methylamine, $50 \mathrm{mM}$ dimethylamine and $50 \mathrm{mM}$ trimethylamine. All tests were performed in two replicates and confirmed by two transfers. The incubation was performed during 10 days. The growth was estimated by measuring the concentration of methane in the gas phase using gas chromatography [8]. The effect of the antibiotics on the growth of strain JL01 was determined using the following antibiotics: (mg l-1) chloramphenicol (10), bacitracin (10), polymyxin (10), vancomycin (2000), erythromycin (1000), kanamycin (2000) and penicillin G (2000).

\subsection{Cooperation study}

A cooperation between Methanosarcina sp. JL01 and S. associata GLS2 ${ }^{\mathrm{T}}\left(\mathrm{VKM}\right.$ B-2742 ${ }^{\mathrm{T}}$ ) was established in anaerobic MSG medium for methanogenic archaea by inoculating $15 \%$ (v/v) of archaeal strain pre-grown on the same medium with methanol and $10 \%(\mathrm{v} / \mathrm{v})$ of bacterial strain grown on SM medium with xylose [9]. For comparison archaeal strain was grown on MSG medium with acetate and methanol. There was also the variation with Methanosarcina sp. JL01, S. associata GLS2 ${ }^{\mathrm{T}}$ and methanol. The experiment was carried out in duplicate at $28^{\circ} \mathrm{C}$. Methane and acetate were monitored immediately after inoculation, then after 1,3,9, and 16 days using gas chromatography.

\subsection{Molecular and phylogenetic analyses}

Extraction and purification of genomic DNA were carried out by a modified Marmur method [10]. The 16S rRNA gene was amplified by PCR using the universal archaeal primers F21-41 [11] and Arch1386r [12]. The A subunit of methyl coenzyme M reductase gene ( $m c r \mathrm{~A})$ was amplified using the 
MCRf and MCR1R primer pair [13]. The $G+C$ content of DNA and DNA-DNA relatedness tests were performed spectrophotometrically.

\subsection{Genomes analysis}

The genome sequence of strain JL01 was determined in the Centre for Genomic Regulation (Barcelona, Spain) and deposited in NCBI under accession number CP029709. The sequencing and annotation of S. associata GLS2 ${ }^{\mathrm{T}}$ genome were carried out at the U.S. Department of Energy Joint Genomic Institute within the project Genomic Encyclopedia of Type Strains, Phase III project (Contract No. DE-AC02-05CH11231). The GLS2 ${ }^{\mathrm{T}}$ whole genome shotgun project (WGS) is available in the GenBank database under the accession number FXUH01000000.

\section{Results and discussions}

\subsection{Enrichment and pure culture isolation}

The initial incubation of the Holocene permafrost sample [1] with acetate resulted in enrichment culture JL01 producing methane at $15^{\circ} \mathrm{C}$. This enrichment contained a stable contaminating bacterial partner identified as S. associata GLS2 ${ }^{\mathrm{T}}$ [9] which coexisted well with methanogen for a long time on the medium under conditions optimal for the methanogen. The concomitant bacterium was resistant to various antibiotics but the methanogenic strain JL01 was purified by repeated transfers. Strain JL01 formed yellow grainy colonies $1 \mathrm{~mm}$ in diameter after 21 days of cultivation. The cells formed small aggregates on the bottom of the cultivation bottles when grown in liquid cultures.

\subsection{Characterization of novel methanogenic strain}

The cells of strain JL01 were non-motile irregular cocci, 1.0-1.5 $\mu \mathrm{m}$ in diameter. They grouped into multicellular aggregates (Figure 1a). Cells stained Gram-positive. The cell wall was $40-50 \mathrm{~nm}$ in width (Figure 1b). Some cells had electron dense inclusions.

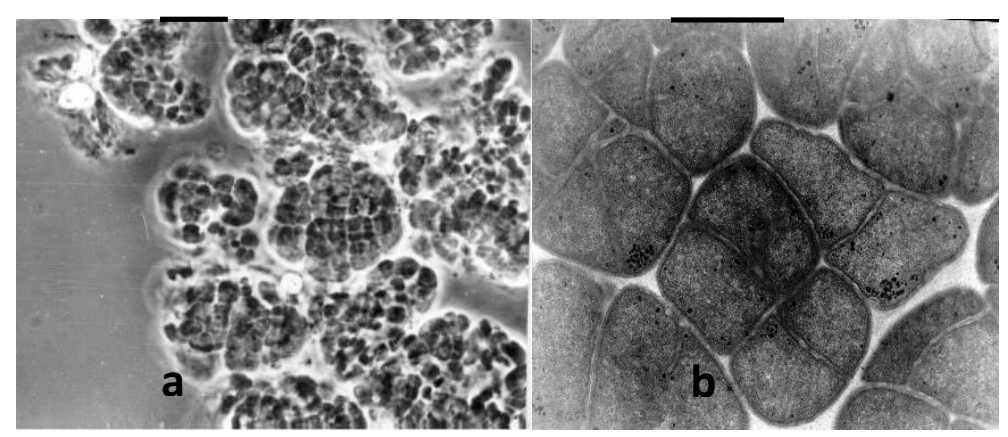

Figure 1. Micrographs of strains JL01 cells: (a) - phase-contrast microscope, bar $10 \mu \mathrm{m}$; (b) - ultra-thin section, bar $1 \mu \mathrm{m}$.

The strain JL01 was a strict anaerobe and grew on methanol, acetate and methylamines as energy and carbon sources. The isolate did not utilize $\mathrm{H}_{2} / \mathrm{CO}_{2}$, formate, 2-propanol, 2-butanol, butyrate, ethanol or propionate as single sources of carbon and energy. The addition of Casamino acids $(1.0 \mathrm{~g}$ $\left.1^{-1}\right)$ to the medium stimulated the growth on methanol and acetate. JL01 grew at temperatures between 10 and $37{ }^{\circ} \mathrm{C}$ (optimum at $24-28{ }^{\circ} \mathrm{C}$ ), $\mathrm{pH} 5.5$ and 8.5, (optimum at 6.8-7.3) and $\mathrm{NaCl}$ concentrations from 0.01 to $0.2 \mathrm{M}$ (optimum at $0.075-0.1 \mathrm{M}$ ). The strain was resistant to penicillin, vancomycin, erythromycin and kanamycin. The addition of bacitracin slowed the growth of the strain.

\subsection{Phylogenetic analyses}

A nearly complete fragment of $16 \mathrm{~S}$ rRNA gene (1370 bp) and a fragment of $m c r$ A gene (512 bp) were amplified from genomic DNA of the isolate JL01. Phylogenetic analysis showed that the 
topology of the tree based on the mcrA does not match the topology of the phylogenetic tree based on the 16S rRNA genes. According the analysis of $16 \mathrm{~S}$ rRNA gene the closest relatives of strain JL01 were M. mazei S-6 $6^{\mathrm{T}}(99.5 \%)$ and M. soligelidi SMA-21 ${ }^{\mathrm{T}}(99.4 \%)$. Comparison of $m c r$ A gene sequences showed that it was $99.4 \%$ identical to $M$. horonobensis strain HB-1T, while 93.1 and $96.2 \%$ to M. mazei and M. solidgelidi, respectively (Figure 2).

The G+C contents of DNA determined by spectrophotometrically in strains JL01 and M. mazei S$6^{\mathrm{T}}$ were 39.2 and $42.3 \mathrm{~mol} \%$, respectively. The results of wet DNA-DNA hybridization indicated only $26.2 \pm 2.7 \%$ relatedness (mean \pm SD of 3 determinations) between strains JL01 and M. mazei S- 6 T.

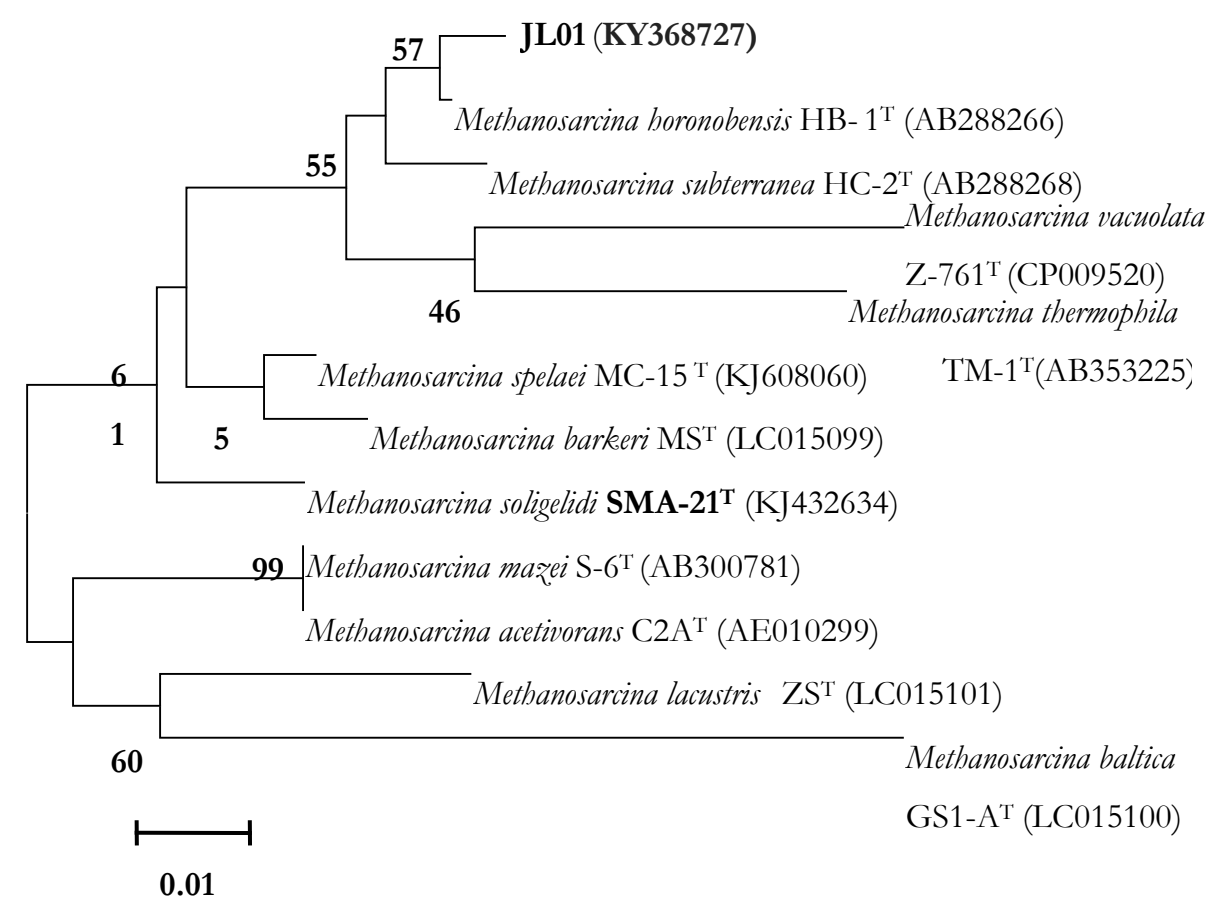

Figure 2. Phylogenetic tree based on mcrA gene sequences showing the relationship between the strain $\mathrm{JL}^{\mathrm{T}}{ }^{\mathrm{T}}$ and other members of the genus Methanosarcina. The numbers at the branch nodes indicate bootstrap percentages based on the neighbor-joining method (1000 replicates). Accession numbers are shown in parentheses.

\subsection{Genome organization of strain JL01}

The genome assembly of strain JL01 contained 323 contigs, which were organized into 1 scaffold. The sequence total and ungapped lengths were 4,186,733 bp and 4,127,022 bp, respectively. Calculated $G+C$ content was $41.59 \%$, contig N50 value is 57,424 bp, $L_{50}$ is 21 . The total count of genes was 3,511, of which there were 3,210 protein coding sequences and 229 pseudogenes. There were 72 RNA genes including 12 rRNA genes, 58 tRNA and 2 ncRNA genes. The JL01 genome had no identified plasmids. It had 7 CRISPR regions predicted with RefSeq and 14 predicted with DFAST. The coding ratio was $73.4 \%$. Genome of strain JL01 contained the key genes of the hydrogenotrophic acetoclastic, and methylotrophic pathways of methanogenesis. The strain lacked some genes encoding proteins involved in coenzyme M synthesis (EC 4.4.1.19, EC 3.1.3.71 and EC 1.1.1.337) and formate dehydrogenase (EC 1.17.1.9, EC 1.17.98.3 or EC 1.17.1.10) genes, which are responsible for the conversion of formate to $\mathrm{CO}_{2}$ in hydrogenotrophic pathway. Genome contained genes for nitrogenase and hydroxylamine reductase. The $\mathrm{G}+\mathrm{C}$ contents of strains JL01 and M. mazei S- $6^{\mathrm{T}}$ were 41.6 and $41.4 \mathrm{~mol} \%$, respectively. The comparison of whole genomic sequences (ANI) of the isolate and the type strain of M. mazei was $98.5 \%$, which is higher than the values recommended for new species $(95-96 \%)$. 


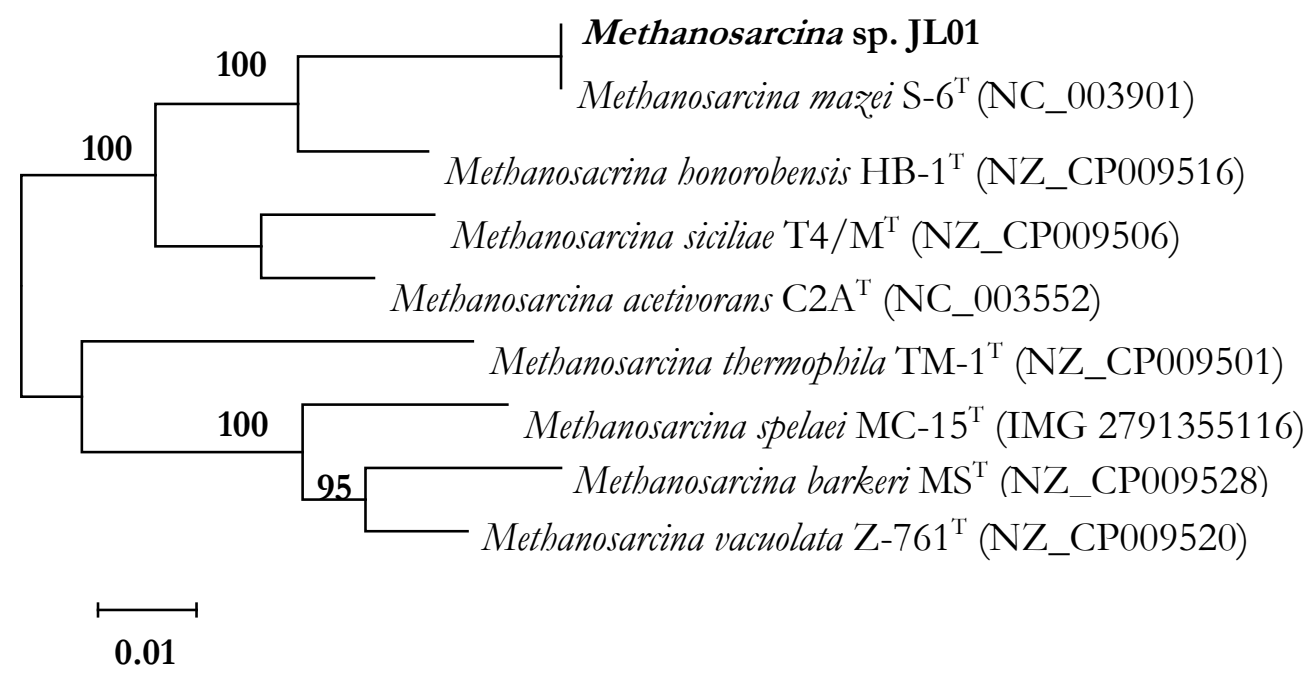

Figure 3. Maximum-likelihood phylogenetic tree of the strain JL01 based on a concatenated alignment of broadly conserved protein-coding genes (bootstrap $=1000$ ). The sequence access numbers publicly available in Genbank are shown in parentheses. Evolutionary analyses were conducted in MEGA7.

\subsection{Co-cultivation M. mazei JL01 and S. associata GLS2T}

A cooperation study between M. mazei JL01 and S. associata $\mathrm{GLS2}^{\mathrm{T}}$ was carried out in methanogenic medium by inoculating of archaeal strain grown with methanol and of bacterial strain grown on SM medium with xylose [9]. The results of co-cultivation on the mineral methanogenic medium showed that the $\mathrm{CH}_{4}$ content in the presence of the bacterium was comparable (Figure 4) to that formed by the strain JL01. The bacterial strain formed acetate during growth on xylose (Figure 5). We suggest that GLS2 was able to ferment the components of methanochondroitin matrix as a substrate with production of acetate.

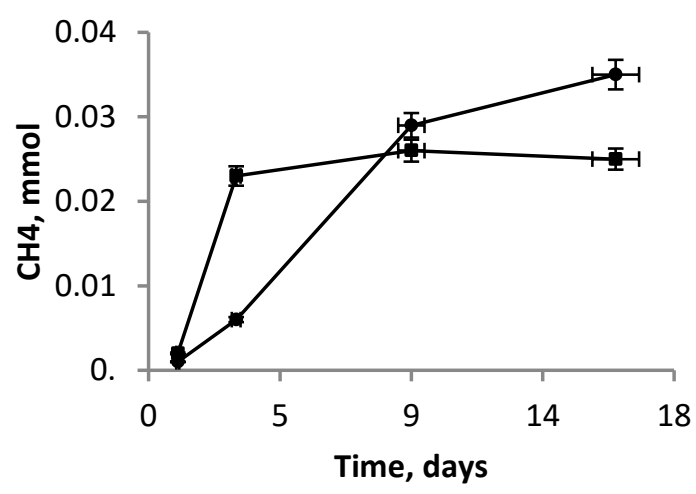

Figure 4. Methane formation by M. mazei JL01 with acetate (circle) and in cooperation with S. associata $\mathrm{GLS}^{\mathrm{T}}$ without any substrates (square). The temperature of cultivation was $28^{\circ} \mathrm{C}$. 


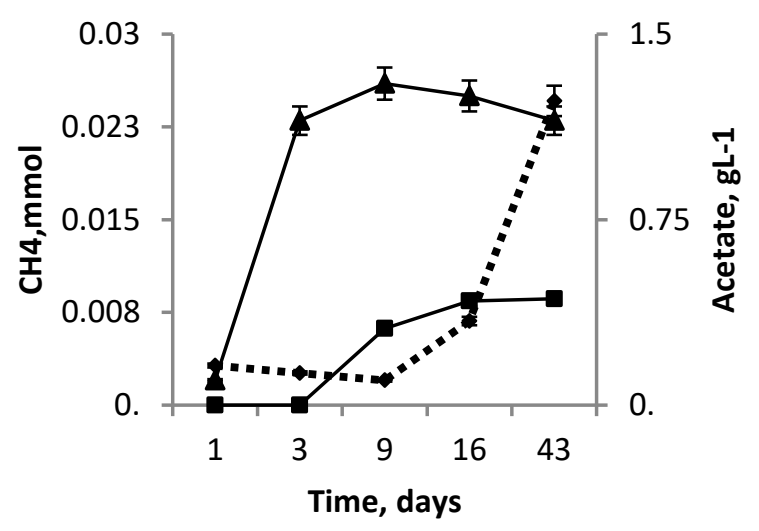

Figure 5. Methane formation by M. mazei JL01 (traingle) and acetate concentration (square) in a mixture with $S$. associata GLS2 ${ }^{\mathrm{T}}$ without substrate addition and acetate production (rhombus) by $S$. associata GLS2 ${ }^{\mathrm{T}}$ with xylose.

\subsection{Genomic data support possibility of the cooperation}

The genome analysis of $S$. associata GLS2 ${ }^{\mathrm{T}}$ showed a high number and diversity of carbohydrate transporters and a moderate diversity of carbohydrate-active enzymes (CAZy enzymes). The profile of CAZy enzymes encoded in genome of GLS2 exhibited the peculiarities reflecting a particular adaptation of this bacterium towards usage of methanochondroitin matrix of methanosarcina. $S$. associata GLS2 ${ }^{\mathrm{T}}$ genome had genes for putative proteins which might be involved in chondroitin usage such as glucoronyl hydrolase (unsaturated chondroitin disaccharide hydrolase) (2 proteins SMP46638, SMP50557) and alginate lyase A1-III/heparinase II/III-like (3 proteins SMP46635, SMP50543, SMP40110). None of genes for putative unsaturated chondroitin disaccharide hydrolase and alginate lyase A1-III/ heparinase II/III-like were found in genome of S. halotolerans 4-11 ${ }^{\mathrm{T}}$ isolated from formation water of a low-temperature petroleum reservoir and just single copies of respective genes were present in genomes of strains S. globosa Buddy ${ }^{\mathrm{T}}$ and S. pleomorpha Grapes ${ }^{\mathrm{T}}$ isolated from river sediments. GLS2 ${ }^{\mathrm{T}}$ genome contained genes for complete glycolytic and oxidative pentose phosphate pathways as well as for further metabolism of pyruvate into lactate (D-lactate dehydrogenase, SMP59869), acetate (acetate kinase, SMP48022), ethanol (acetaldehyde dehydrogenase/alcohol dehydrogenase AdhE, SMP46078), formate (formate C-acetyltransferase, $\mathrm{SMP} 45624)$ and $\mathrm{CO}_{2}$.

JL01 genome had almost complete pathway of cobalamin biosynthesis, in contrast to GLS2 ${ }^{\mathrm{T}}$ genome which showed the presence of only four enzymes of cobalamines "salvage pathway".

JL01 and GLS2 genomic data pointed out on complementary capabilities of partners in amino acids biosynthesis. JL01 had complete tryptophan biosynthesis pathway beginning from chorismate, while GLS2 had 4 genes missing. At the same time GLS2 had a complete set of genes in shikimate pathway leading to chorismate which is an important biochemical intermediate in biosynthesis of tryptophan, phenylalanine, tyrosine and folates. GLS2 genome showed the presence of complete histidine, threonine, cysteine, leucine pathways, while JL01 genome showed one to several missing steps in them.

Thus obtained data indicate highly complex interactions in consortium of methanosarcina and GLS2. Genomic data point out on possibility of GLS2 to use components of methanochondroithine matrix and to produce acetate, a number of amino acids and intermediates that could be used by methanosarcina, while methanosarcina in its turn fixes molecular nitrogen and produces other biosynthetically complex compounds such as cobalamines and tryptophan. We hypothesize that JL01 and GLS2 demonstrate strict mutualistic multiple interactions by exchanging metabolites of high energy demand which contribute to energy conservation under energy and nutrition-limited conditions in permafrost environment.

\section{Conclusions}


Methanogens of Methanosarcina genus are of great ecological importance as they are the only organisms fermenting acetate, methylamines and methanol to methane, carbon dioxide and ammonia (in case of methylamines). Since acetate is the precursor of $60 \%$ of the methane produced on earth these organisms contribute significantly to the production of this greenhouse gas. Moreover, methanogenic archaea of Methanosarcinales order is most often found among Euryarchaeota in an array of metagenomic data from samples of permanently frozen sediments such as permafrost [2]. The analysis of genomes of some bacteria of Sphaerochaeta genus showed the absence of several genes coding for vitamin $B_{12}$ synthesis. Methanogenic archaea can produce its precursors [14] and can supply them to the bacterium. This facts explain the close cooperation of both GLS2 ${ }^{\mathrm{T}}$ and JL01 and allow to assume that M. mazei JL01 takes advantage in the permafrost ecosystem from coexistence with a bacterial strain. We hypothesize that conditions of $\mathrm{GLS2}^{\mathrm{T}}$ presence in the matrix of Methanosarcina exerted a selection pressure on the bacterial co-habitant leading to the acquirement of necessary genes for the usage of plentiful carbohydrate, a main compound of the extracellular matrix of Methanosarcina. Subsequent lengthy co-cultivation experiments at subzero temperature will give us the final answer to this key question of microbial activity in permafrost.

Funding: The work was supported by of Russian Foundation of Basic Research: grant № 19-04-00831 for Viktoria Shcherbakova and Olga Troshina, grant № 18-34-00334 for Viktoriia Oshurkova and Vladimir Trubitsyn.

Acknowledgments: We thank Dr Natalia Suzina (IBPM RAS, Federal Research Center Pushchino Center for Biological Research RAS) for the help with the microscopic studies, respectively; Dr. Margarita Meyer (Division of Genetics, Department of Medicine, BWH and HMS, USA) and Dr Fedor Kondrashov (IST, Austria) for their help in obtaining the genomic sequence of strain JL01.

Conflicts of Interest: The authors declare no conflict of interest.

\section{References}

1. Rivkina, E.; Shcherbakova, V.; Laurinavichius, K.; Petrovskaya, L.; Krivushin, K; Kraev, G.; Pecheritsina S; Gilichinsky, D. Biogeochemistry of methane and methanogenic archaea in permafrost. FEMS Microbiol Ecol 2007, 61(1),1-15.

2. Shcherbakova, V.; Yoshimura, Y.; Ryzhmanova, Y.; Taguchi, Y.; Segawa, T.; Oshurkova, V.; Rivkina, E. Archaeal communities of Arctic methane-containing permafrost. FEMS Microbiol Ecol 2016, 92(10).

3. Rivkina, E.; Laurinavichius, K.; McGrath, J.; Tiedje, J.; Shcherbakova, V.; Gilichinsky, D. Microbial life in permafrost. Advances in Space Research, 2004, 33(8), 1215-1221.

4. Krivushin, K.V.; Shcherbakova,V.A.; Petrovskaya, L.E.; Rivkina, E.M. Methanobacterium veterum sp. nov., from ancient Siberian permafrost. IJSEM 2010; 60:455-459.

5. Shcherbakova, V.; Rivkina, E.; Pecheritsyna, S.; Laurinavichius, K.; Suzina, N.; Gilichinsky, D. Methanobacterium arcticum sp. nov., a methanogenic archaeon from Holocene Arctic permafrost. IJSEM 2011, 61(1), 144-147.

6. Rivkina, E.; Petrovskaya, L.; Vishnivetskaya, T.; Krivushin, K.; Shmakova, L.; Tutukina, M.; Meyers, A.; Kondrashov, F. Metagenomic analyses of the late Pleistocene permafrost-additional tools for reconstruction of environmental conditions. Biogeosciences 2016, 13(7).

7. Morris, B.E.; Henneberger, R.; Huber, H.; Moissl-Eichinger, C. Microbial syntrophy: interaction for the common good. FEMS Microbiol Rev. 2013, 7(3):384-406.

8. Boone, D.R.; Whitman, W.B. Proposal of minimal standards for describing new taxa of methanogenic bacteria. Int J Syst Bacteriol 1988, 38:212-219.

9. Troshina, O., Oshurkova, V., Suzina, N.; Machulin, A.; Ariskina, E.; Vinokurova, N.; Kopitsyn, D.; Novikov, A.; Shcherbakova, V. Sphaerochaeta associata sp. nov., a spherical spirochaete isolated from cultures of Methanosarcina mazei JL01. IJSEM 2015, 65(12), 4315-4322.

10. Marmur, J.; Doty, P. Thermal renaturation of deoxyribonucleic acids. J Mol Biol 1961, 3: 585-594.

11. DeLong, E.F. Archaea in coastal marine environments. PNAS 1992, 89(12): 5685-5689.

12. Kittelmann, S.; Seedorf, H.; Walters, W.A.; Clemente, J.C.; Knight, R.; Gordon, J.I.; Janssen, P. H. Simultaneous amplicon sequencing to explore co-occurrence patterns of bacterial, archaeal and eukaryotic microorganisms in rumen microbial communities. PLoS ONE 2013, 8:e47879. 
13. Springer, E.; Sachs, M.S.; Woese, C.R.; Boone, D.R. Partial gene sequences for the A subunit of methylcoenzyme M reductase (mcrA) a phylogenetic tool for the family Methanosarcinaceae. Int J Syst Bacteriol 1995, 45:554-559.

14. Zhang, G.; Jiang, N.; Liu, X.; Dong, X. Methanogenesis from methanol at low temperatures by a novel psychrophilic methanogen, "Methanolobus psychrophilus" sp. nov., prevalent in Zoige wetland of the Tibetan plateau. Appl Environ Microbiol 2008, 74 (19): 6114-6120.

Publisher's Note: MDPI stays neutral with regard to jurisdictional claims in published maps and institutional affiliations.

(C) 2020 by the authors. Submitted for possible open access publication under the terms and conditions of the Creative Commons Attribution (CC BY) license (http://creativecommons.org/licenses/by/4.0/). 